\title{
Using volunteered geographical information to map the November 2012 floods in Slovenia
}

\author{
M. Triglav-Čekada and D. Radovan \\ Geodetic Institute of Slovenia, Ljubljana, Slovenia \\ Correspondence to: M. Triglav-Čekada (mihaela.triglav@gis.si) \\ Received: 15 May 2013 - Published in Nat. Hazards Earth Syst. Sci. Discuss.: 25 June 2013 \\ Revised: 12 October 2013 - Accepted: 14 October 2013 - Published: 5 November 2013
}

\begin{abstract}
Volunteered geographical information represents a promising field in the monitoring and mapping of natural disasters. The contributors of volunteered geographical information have the advantage that they are at the location of the natural disaster at exactly the time when the disaster happened. Therefore, they can provide the most complete account of the extent of the damage. This is not always possible when applying photogrammetric or remote-sensing methods, as prior to the data acquisition an order to carry out the measurements has to be made. On 5 and 6 November 2012 almost half of Slovenia was badly affected by floods. The gathering of volunteered geographical information in the form of images and videos of these floods is presented. Two strategies were used: (1) a public call for volunteered contributions and (2) a web search for useful images and their authors. The authorship of these images was verified with every contributor. In total, 15 contributors provided 102 terrestrial and aerial images and one aerial video, with $45 \%$ classified as potentially useful. For actual flood mapping 22 images and 12 sequences from video were used. With the help of the volunteered images $12 \%$ of the most severely affected river sections were mapped. Altogether, 1195.3 ha of flooded areas outside of the usual river beds along a total river length of $48 \mathrm{~km}$ were mapped. The results are compared with those from satellite mapping of the same floods, which successfully covered $18 \%$ of the most affected river sections.
\end{abstract}

\section{Introduction}

Knowledge about the extent of natural disasters is important for disaster management. Natural events are in fact difficult to prevent and mitigation measures are indispensable when it comes to reducing their damaging effect. Disaster management includes risk reduction by means such as spatial planning, technical measures and improvement of public awareness (Poser and Dransch, 2010). The public can help to delineate the extent of natural disasters through volunteered geographical information (McDougall, 2012). In this article the example of the Slovenian flood of November 2012 is used to present the flood-extent mapping resulting from volunteered geographical information.

The extent of floods can be measured by different remotesensing methods, from aerial photogrammetry to highresolution satellite data (e.g., Lane et al., 2003; Schumann et al., 2011). Such remote-sensing acquisitions have to be carried out within a maximum of a few days after the event, as the floods recede quickly. Often, after major events, bad weather conditions hinder the successful acquisition of optical satellite or aerial photogrammetric data. In addition, the limited spatial resolution of satellite data may hinder the detection of small flooded areas in vegetated, commercial or residential areas (McDougall and Temple-Watts, 2011). The order of the flood-data acquisition cannot be completed during the time of the disaster: therefore, only some kind of postmaximum extent of the natural disaster can be measured using traditional means.

In contrast, volunteered geographical information can record the maximum extent of a natural disaster at the exact time of its occurrence, as the contributors usually live in the vicinity of the affected areas and so are affected by it. Additionally, volunteered geographical information is not hindered by weather conditions. Volunteered geographical information, as defined by Goodchild (2007), describes humans as sensors giving voluntarily temporal and spatial geographical information in the form of images, videos, sounds and text 
messages. Some data are already geolocated automatically, while others can be geolocated during the data processing. In the case of floods the volunteered geographical information can help to fill the gaps in the satellite imagery (Schnebele and Cervone, 2013) or can be used as stand-alone information (Poser and Dransch, 2010; McDougall and TempleWatts, 2012). The volunteered geographical information can also be used for assessing the extent of other natural disasters, as for example the New Zealand earthquake of 2011 and the Japanese tsunami of 2011 (McDougall, 2012).

Almost every year, local heavy rain induces floods in Slovenia to a lesser or greater extent. Due to the country's diverse topography, which causes extensive climatic variability over short distances, these floods are mainly local and tend to occur in late summer and autumn (Rusjan et al., 2009). However, the heavy rains between 4 and 5 November 2012 caused extensive floods, affecting areas of all the major rivers covering the majority of the northern half of Slovenia on 5 and 6 November 2012. Between 4 and 6 November up to $280 \mathrm{~mm}$ of rain fell on the mountain ranges in northwestern Slovenia, up to $160 \mathrm{~mm}$ on the mountain ranges in northern Slovenia, between $30 \mathrm{~mm}$ and $100 \mathrm{~mm}$ in central Slovenia, and $20 \mathrm{~mm}$ to $50 \mathrm{~mm}$ on the southern part of Slovenia. Prior to this rainfall the soil was already heavily soaked because of the rain that fell a week earlier. This caused the water level in the rivers to increase dramatically and the water to spill over in the form of floods (ARSO, 2012).

This paper gathers the volunteered geographical information in the form of amateur images and uses them as the main source of data to delineate the extent of the floods. In Sect. 2 the study area and additional data used in the study are presented. The data gathering and the methods are presented in Sect. 3. In Sect. 4 the percentage of the areas mapped with the volunteered images compared to the total extent of the flooding is derived. Additionally, the results of flood mapping from satellite images are compared to the flood mapping from the volunteered images. In Sect. 5 proposals are given for future actions. The volunteered geographical images used in this example have demonstrated a great potential for detailed flood mapping.

\section{Data}

\subsection{Study area}

On 5 and 6 November 2012 floods affected almost the whole northern half of Slovenia. The gathering of volunteered images was designed to cover as broad an area as possible. The data gathering of the volunteered images and the methodology for the data acquisition is described in detail in the next section. The total extent of the floods can be described with the most affected rivers, which are drawn in Fig. 1.

\subsection{Additional data - satellite mapping products}

For the comparison of results gained with the volunteered image gathering, additional satellite mapping products were used. These were already-interpreted flood maps from "GIO EMS Mapping products" showing flooded areas at generaloverview topographic scales of $1: 45000$ and $1: 55000$, presented in Fig. 1 in a yellow color. For some smaller parts inside those areas, detailed maps on a scale of $1: 15000$ were also available. The GIO EMS mapping products are based on satellite images and were produced in rush mode (EMS - mapping portal, 2013). The acquisition of satellite images of the flooded areas and the production of flood-extent maps were triggered with the activation of the GIO EMS system by the authorized user - the Administration for Civil Protection and Disaster Management of the Ministry of Defence of the Republic of Slovenia.

For this research, only satellite mapping products were available; there were no raw satellite images. Satellite mapping products consist of vector or raster flood maps, which present the borders of flooded areas, the main rivers, roads and settlements. The flooded areas are extracted from the satellite images by means of semi-automatic classification processing techniques. The other general information is derived from Wikimapia, Openstreetmap and Geonames (rivers, roads, settlements). The new vector data is presented on the older satellite images in false colors with a ground sampling distance of $2.5 \mathrm{~m}$ (Fig. $4 \mathrm{~b}$ and d). The estimated thematic accuracy of this product is $85 \%$ or better, although it may be lower in urban and forested areas. The satellite mapping products, which in this paper will be called satellite maps, refer to the most prominent city on the satellite image and are numbered in Fig. 1: Ljubno (1), Dravograd (2), Ptuj (3), Ormož (4), and Krško (5). The flooded areas were derived from COSMO-SkyMed images (COSMO-SkyMed, 2013) with a ground sampling distance of $5 \mathrm{~m}$ for Ptuj (3), Ormož (4), Krško (5), and Dravograd (2), or TerraSAR-X images (TerraSAR-X, 2013) with a ground sampling distance of $3 \mathrm{~m}$ for Ljubno (1). The images for Ptuj (3) and Ormož (4) were acquired one day after the floods; for Krško (5) it was two days, Dravograd (2), three days, and Ljubno (1), four days after the floods.

\section{Methodology}

For the gathering of volunteered geographic information in the form of images and videos, two strategies were used: (1) a public call for volunteered contributions and (2) a web search for useful images. The useful images enabled floodarea mapping by means of an interactive orientation of images based on a digital terrain model (DTM). The results are compared with the flooded areas presented on satellite maps. 


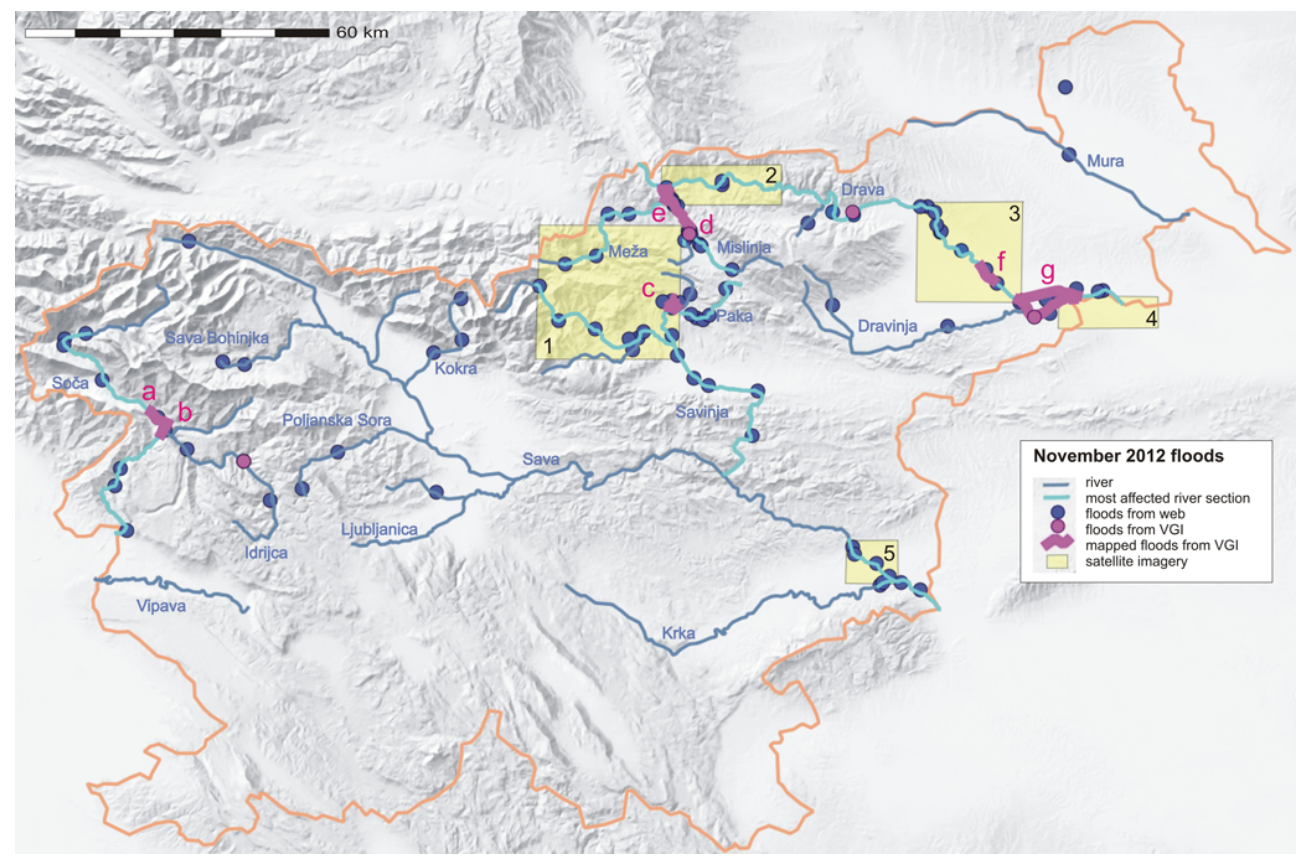

Fig. 1. The extent of the November 2012 floods in Slovenia. The satellite maps are numbered from (1) to (5), the floods mapped from volunteered images from (a) to (g).

\subsection{Gathering of volunteered images}

On the web page and Facebook profile of the Geodetic Institute of Slovenia (GIS, 2012), an open call to gather volunteered geographic images covering the 2012 floods was published on the second day of the floods, 6 November 2012. With the help of extensive social networking, the information on the call propagated quickly through the social media. A major increase in the collaboration of the public was observed in the number of visits to both profiles over the next few days. In the first four days after the publication of the call the web page had seven times more views than on ordinary days. The views of the Facebook profile were even more numerous. In the first week after the announcement, the number of daily views of the Facebook profile rose to 16 times as many views as on the days before the call. A maximum of 700 views per day was observed during the first few days after the announcement.

The majority of contributors posted data on the floods when the floods were still "headline news", less than a week after the floods. Some occasional contributions happened even after those dates, mainly when the action was reported on television and radio. The action was terminated two months after the floods when no more contributions were received. The first results in the form of flood maps were published on the web page and Facebook profiles two weeks after the event to encourage additional potential contributions. The final results were published in the same way four months after the floods. The first results and the final results were also presented on national television.
To illustrate the kinds of images we were searching for, an example was provided on the Facebook and web pages, showing a 2010 flood image accompanied by the flood extent derived from that image. An additional text described the kinds of images we were searching for (GIS, 2012):

"If you have an image of flooded areas covering as wide an area as possible, taken from a higher standpoint (e.g., from the upper floor of a building, from a hilltop), please send it to poplave@gis.si. It is better if at least two to three roads or part of a hill are recognizable on the image.

Please add the following information in the e-mail:

- a broad description of the area that is shown on the image

- the date and the approximate time when the image was taken

- the approximate standpoint (location of imaging)

- the author of the image."

Special care was taken to ensure that all the data gained as a result of the call were checked in terms of authorship.

A total of 15 contributions were received, with 5 contributors sending images taken by someone else (Table 1). This was discovered when the contributor was asked whether he was the author of the images. In the majority of cases when the contributor sent the images from someone else it was impossible to find out who the author was, as the source was e-mailing from a "friend of a friend". If the contributor was 
Table 1. The number of contributors of volunteered images for the November 2012 floods in Slovenia.

\begin{tabular}{llll}
\hline & Contacts & $\begin{array}{l}\text { Cannot } \\
\text { be used }\end{array}$ & $\begin{array}{l}\text { Can be } \\
\text { used }\end{array}$ \\
\hline (1) public call - volunteered contribution with authorship & 10 & 0 & 10 \\
(1) public call - volunteered contribution without authorship & 5 & 5 & 0 \\
(2) web search - contacting author & 6 & 1 & 5 \\
\hline
\end{tabular}

also the author of the image, he/she agreed that his/her intellectual property (in this case the image) could be used for free for research purposes. If the contributor sent images from an unidentified author, the images were not used.

\subsection{Web search for volunteered images}

Simultaneously, during the first two weeks after the floods, a search of various social media networks (Youtube, Mojalbum) and local web news was made to find already-available images of the floods, which could have the potential for flood-extent mapping. When such an image or video was found, attempts were made to contact the author of the image. Even though different licenses for using Facebook, Youtube and other social media networks' data already exist and mainly define open access to such data, national legal property laws provide more strict regulations, especially concerning the intellectual property of images (Scassa, 2013). Therefore, caution was necessary, as some authors present their images on web networks in order to attract attention from television and printed media, who they hope might purchase their images. Without contacting such a person, it was not possible to know if he/she was willing to offer his/her image for free. Six potential contributors of appropriate images were contacted (Table 1). Only one author refused to allow his images to be used for research purposes for free.

Different local media, public clubs and local fire brigades also gathered images of the floods. Some of them were aware of the problems regarding authorship and possible unapproved usage of such images, others were not. Those who were aware had on their web pages, which presented the images from different authors, additional disclaimers, mainly stating something like this: "You may not use these images without the approval of the image's author".

In general it was found that much more time was needed to obtain a reply from an author of a potentially useful image found by a web search than to get approval for voluntarily given images. In the first case, it usually took two steps: first the owner of the web page was contacted and asked for information about the image's author, then the author was contacted. The authors were sometimes hidden behind their nicknames. To reach the author of Youtube material, you can only write a comment under the video and then wait for the author to respond.

\subsection{Selection of images for mapping}

All the contributed images could be used to map the floods. Some of them reveal smaller areas, while others cover larger areas. To map the floods as soon as possible, it was decided that in the first place only the most appropriate images should be used. The other images, showing narrower scenes, were classified as images for documentation and were not used for the mapping.

The results and selected images were presented on our web pages and Facebook site (GIS, 2012). However, those images that might have violated privacy were excluded, as proposed by Scassa (2013). Therefore, images showing people were not used in any presentation.

Altogether, 15 contributors with confirmed authorship provided useful collaborative visual data (Table 1), consisting of 102 terrestrial and aerial images and one aerial video. Some $45 \%$ of them were classified as potentially useful for floodextent mapping. For the actual flood mapping, 22 images and 12 sequences from the video were used, representing only $21 \%$ of the gathered images.

\subsection{Mapping floods in 3-D}

To acquire a 3-D boundary of the floods, an interactive method for the absolute orientation of the images based on the digital terrain model (DTM) was used. The method is roughly described below, while the details can be found in Triglav-Čekada et al. (2011) and Rönnholm et al. (2003).

The absolute orientation parameters of an individual image (i.e., the 3-D location of the standpoint, the three angles of the image orientation and the scale) were derived with a manual interactive search for the best fit of the superimposed 3-D points of the DTM onto the details seen on the image. When the image is orientated correctly, the superimposed DTM points fit to the distinct details seen on the image very well. Karjalainen et al. (2006) proposed an interactive orientation based solely on vector break lines (roads, rivers); therefore, our method was also amended with break lines (Fig. 2). The 3-D boundary of the flooded area is measured by selecting individual 3-D points from the superimposed DTM.

The photogrammetrically derived DTM with a cell size of $5 \mathrm{~m} \times 5 \mathrm{~m}$ was used for the orientation of the images and the acquisition of flooded areas. It was produced in 2006 and it covers the entire country of Slovenia. The accuracy of the DTM is variable, as it depends on the type of vegetation 


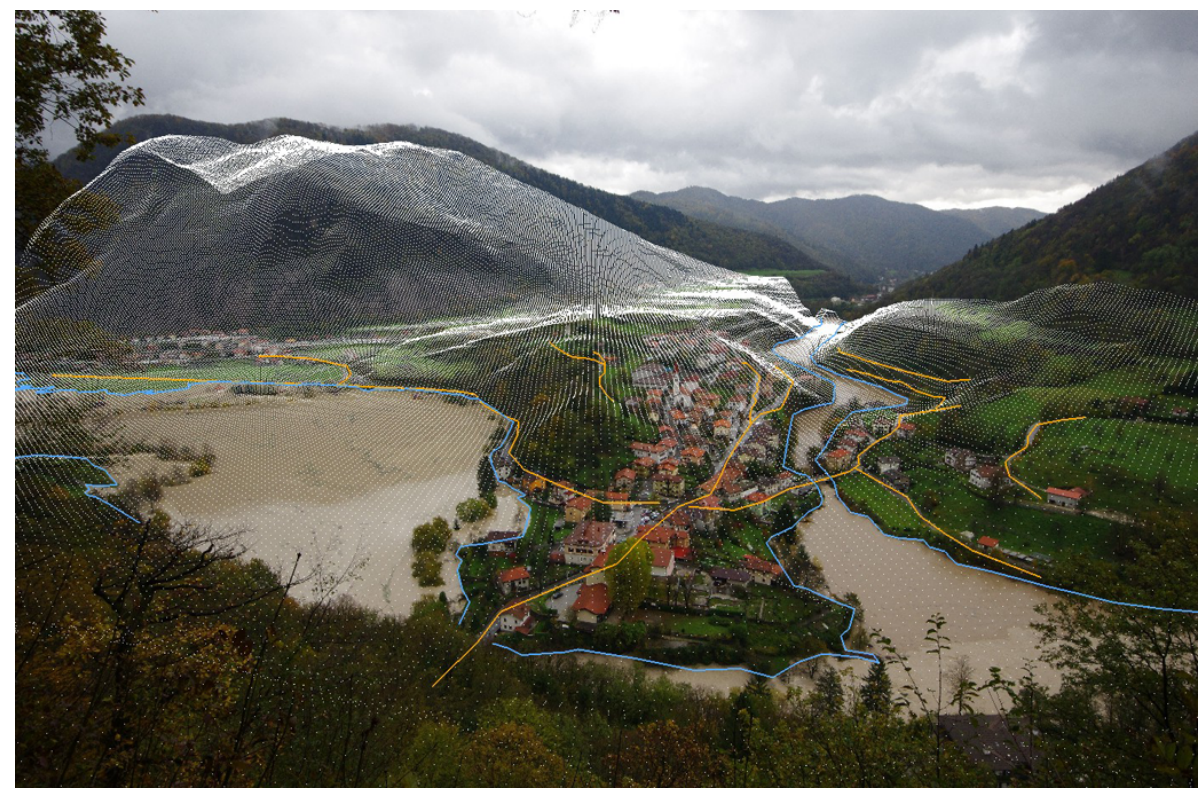

Fig. 2. Digital terrain model (white), roads (brown) and border of the flooded area (blue) superimposed on the image of the floods in Most na Soči on 5 November 2012 around 13:00 (marked with (b) in Fig. 1). The author of the underlying image is Miljko Lesjak.

cover. In the lowlands where the floods occurred, the maximum expected elevation errors do not exceed $1 \mathrm{~m}$ (SMA RS, 2013).

The most useful images for mapping larger areas were oblique images taken from the air. Since such an image does not have any approximate location of its standpoint, the interactive orientation of such images was exceptionally time consuming.

The borders of the flooded areas were sometimes obstructed by objects (e.g., trees). Since photographs were taken from the nearby hills at very oblique views, the borders of the flooded areas have gaps (Fig. 2). To calculate the area of the floods, the gaps were connected during postprocessing by applying the corresponding height contours between two detached segments. Additionally, the elevation of the water was measured when drawing the flood border on the DTM.

\section{Results}

\subsection{Coverage of the November 2012 floods based on volunteered images}

The general map of the November 2012 floods in Slovenia is presented in Fig. 1. It is based on the information described in local news, images and videos found on the web at the time of writing this paper (e.g., Dravograd Municipality, 2012; Dnevnik, 2012; Velenje, 2012). Only the major rivers affected by the floods are presented. Though the smaller rivers and rivulets were also flooding, due to generalization, they are not presented on the map. The minor floodings of roads are not included on the map as those occurred almost everywhere in the northern part of Slovenia. Landslides were observed during the floods too, but they are not presented on the map.

Altogether, more than 35 web sources were inspected. On average, three to five locations were found in every web source of local news (e.g., local web news, local fire-brigade web announcements). The blue dots in Fig. 1 mostly relate to more than just one web source. The most affected sections of the rivers are colored with a light-blue line. The criteria for mapping the most affected river parts is that more than three flood-describing locations were found in the overview of the web sources. Altogether, the most affected sections sum up to more than $400 \mathrm{~km}$ of the Soča, Sava, Krka, Savinja, Paka, Meža, Mislinja and Drava rivers. This estimation is in good agreement with the general description of the floods prepared by the Slovenian Environment Agency (ARSO) based on the hydrological responses of the rivers (ARSO, 2012).

The pink areas in Fig. 1 represent the mapped flooded areas from the volunteered images. The areas for which we have images that are not useful for the flood-extent mapping using our method are marked with pink dots. In total, $48 \mathrm{~km}$ or $12 \%$ of the most affected river sections were covered by acceptable volunteered images. Even though this share is not very high, it covers the majority of the most affected river segments. Of these most affected rivers, just the flooding of the Savinja and Sava rivers has not been covered at all. Altogether, 1195.3 ha of flooded areas outside of the normal river banks were mapped from volunteered images (Table 2). The total flooded area, where the area of the normal river bed is also included, accounts for 1439.4 ha. 


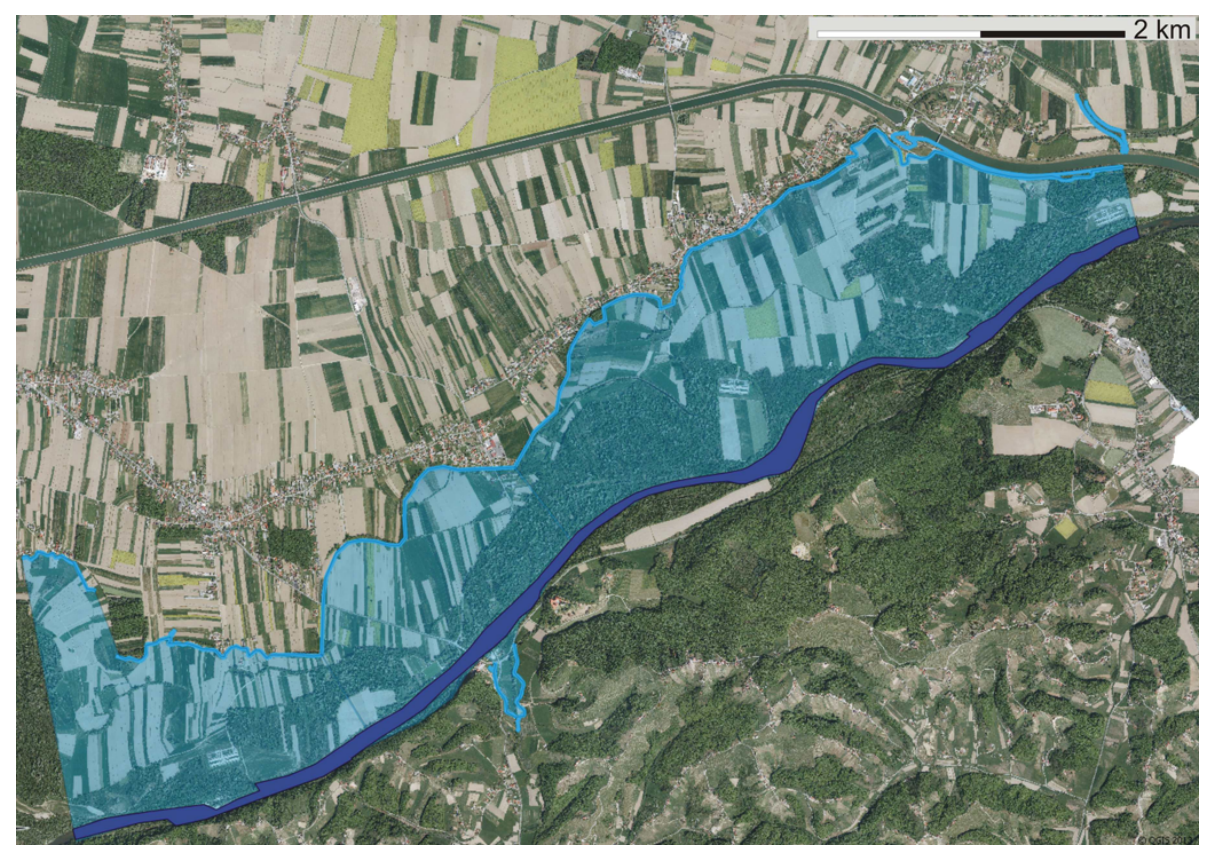

Fig. 3. Floods of the Drava river on 6 November 2012 between Lake Ptuj and Formin (marked with (g) in Fig. 1), derived from volunteered images and presented on the national orthophoto.

Table 2. The extent of the flooded river sections acquired from the volunteered images: the river length, the area covered by the river prior to the flooding and the total flooded area with the included river area. In the first column the areas are marked as in Fig. 1.

\begin{tabular}{lllll}
\hline Settlement names (river names) & $\begin{array}{l}\text { River } \\
\text { length } \\
{[\mathrm{km}]}\end{array}$ & $\begin{array}{l}\text { River } \\
\text { area } \\
{[\mathrm{ha}]}\end{array}$ & $\begin{array}{l}\text { Total } \\
\text { flooded } \\
\text { area [ha] }\end{array}$ \\
\hline a & Tolmin (Soča) & 2.7 & 72.0 & 81.8 \\
b & Most na Soči (Soča) & 2.4 & 24.0 & 38.5 \\
c & Soštanj (Paka, Toplica, Klančnica) & 4.6 & 1.8 & 56.5 \\
d & Pameče (Mislinja) & 1.8 & 1.9 & 16.3 \\
e & From Bukovska vas to Dravograd (Mislinja, Meža) & 5.9 & 8.1 & 111.2 \\
f & From Zlatoličje to Ptuj (Drava) & 4.6 & 67.7 & 234.6 \\
g & From Lake Ptuj to Formin (Drava, Formin canal) & 26.0 & 68.6 & 900.5 \\
\hline & Sum & 48.0 & 244.1 & 1439.4 \\
\hline
\end{tabular}

In Fig. 3 the flooding of the Drava river from Lake Ptuj to Formin is presented (marked with (g) in Fig. 1 and Table 2). It represents the most extended flooded area in our research, with a coverage of 900.5 ha. Seven images from three different contributors were used for the acquisition of the flood borders. Four images were taken from the air to show the extent of the flood imaging for the local television, with three from the hills on the south side of the Drava river.

\subsection{Comparison with satellite maps}

For some of the flooded areas, satellite maps were available. Unfortunately, the satellite maps were based on satellite images taken a day or even four days after the floods, when the majority of the water had already receded. Therefore, only the remaining disconnected water ponds were found on the satellite maps. With some generalization (i.e., aggregation) those water ponds could be connected in larger flooded areas only for the satellite maps of Ptuj and Ormož (marked with (3) and (4) in Fig. 1), for which the original satellite images were acquired on 7 November 2012, one day after the floods. However, even if we do connect the water ponds derived from the satellite maps, we do not get the full extent of the floods as mapped with the help of volunteered images from a day before. This can be seen in Fig. 4, where the only two parts of the overlapping maps are presented. Figure $4 \mathrm{a}$ and $\mathrm{b}$ represent the area marked with (f) in Fig. 1, from Zlatoličje to Ptuj (a part of satellite map (3)), where the flooded area outside the normal river banks receded in one day from 166.9 ha, as 

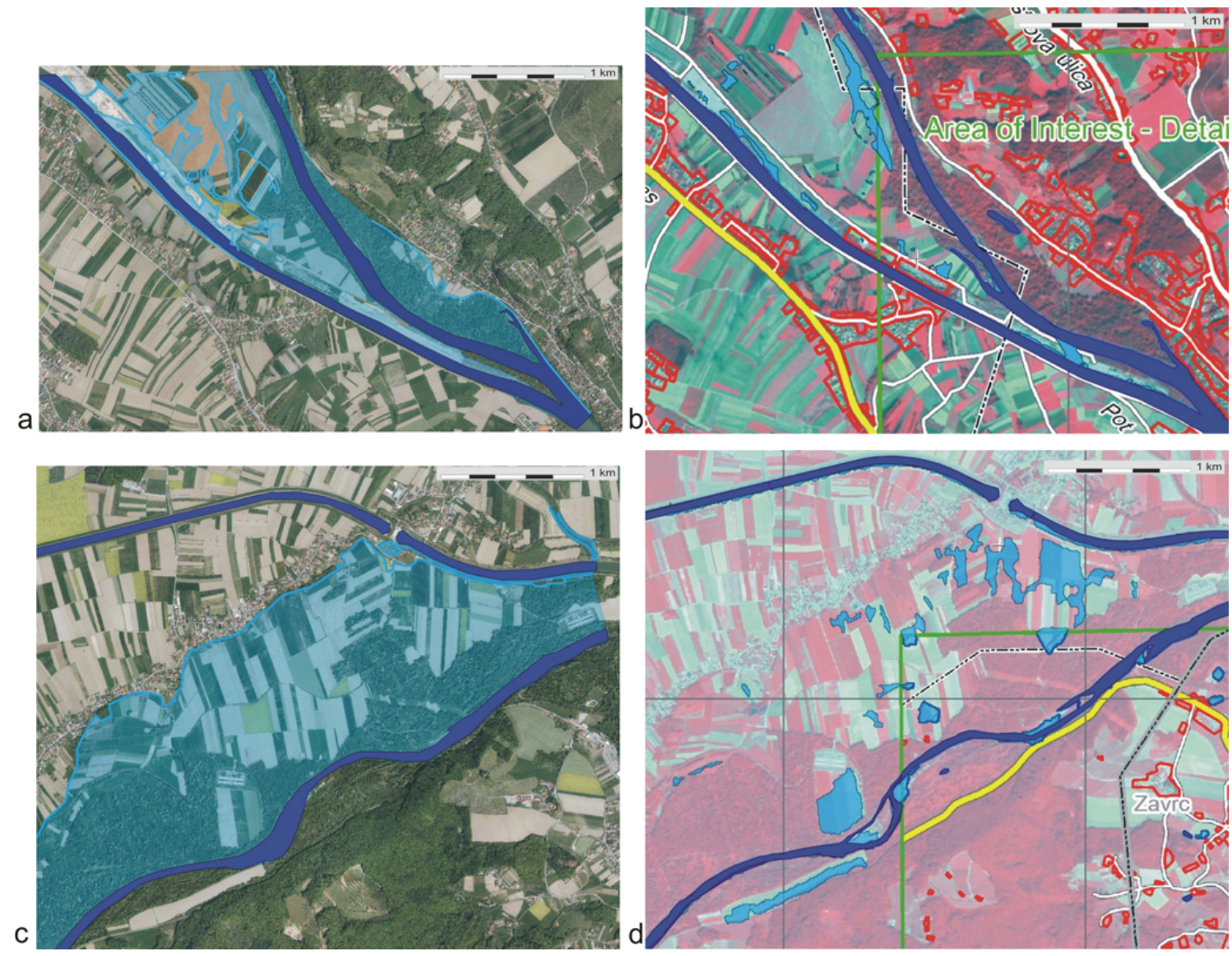

Fig. 4. The flooded areas derived from volunteered images on 6 November (left) and the same detail from the satellite map made on 7 November (right). First row: the area from Zlatoličje to Ptuj (marked with (f) in Fig. 1). Second row: a part of the area from Lake Ptuj to Formin (marked with (g) in Fig. 1). The dark blue areas are the normal river areas and the light blue are the flooded areas. The flooded area from the volunteered images represents water areas connected to the river bed, while the satellite maps show disconnected water ponds.

mapped by the volunteered images on 6 November, to 15.4 ha as presented on the satellite map from 7 November. One day after the floods, less than $10 \%$ of the flooded areas remained. Figure $4 \mathrm{c}$ and $\mathrm{d}$ represent a part of the area from Lake Ptuj to Formin, marked with $(\mathrm{g})$ in Fig. 1 (a part of satellite map (4)). The flooded area (with the normal river bed excluded) receded from 653.7 ha to 53.0 ha in one day; so on the second day only $8 \%$ of the area remained flooded. These two bitemporal results give us a clear idea of the usability of the volunteered images taken in real time or at least in near-real time.

The semi-automatic classification of flooded areas has problems with classifying water bodies in forested areas (Fig. 4d). This is because the identification of flooded areas under vegetation cover is not a trivial task. From the volunteered images the flooded areas under the forest can be assessed manually, based on the altitude variations of the DTM when the flood borders are superimposed on it. If the flooded area is located at the same, or an even higher elevation than the DTM under the forested area, then it is very likely that the forested area is also flooded. In this way the flooded areas in the forest in Fig. 3 were derived.

The Krško satellite map (numbered (5) in Fig. 1) was produced from a satellite image acquired on 8 November 2012, two days after the floods. Nevertheless, some isolated water ponds along the Sava river are represented on it. They are too far away from each other to enable assumptions about the extent of the flood two days before. However, we consider these mapping results to be successful, to a limited extent.

The satellite map of Dravograd (numbered (2) in Fig. 1), acquired on 9 November, three days after the floods, and of Ljubno (numbered (1) in Fig. 1), acquired on 10 November, four days after the floods, can only be taken as mere general information about the presence of floods. The map of Dravograd shows only some extra water on the Drava river banks, while no disconnected water ponds outside the riverbed remained. The extensive flooding of the rivers Meža and Mislinja cannot be observed in this satellite map for the same reason. 
The satellite map of Ljubno still shows a few flooded areas along the Savinja river, which are no more than $10 \mathrm{~m}$ wide. The semi-automatic classification has also misclassified snow-covered areas in the mountains as being flooded.

When summing the results of the satellite mapping that at least partly cover the floods, it can be concluded that a total length of $75.8 \mathrm{~km}$ of the most affected river sections was successfully covered by this method, representing $18 \%$ of the most affected river sections. The following river sections were at least partly covered by satellite maps: the Drava river on the maps of Ptuj and Ormož (numbered (3) and (4) in Fig. 1), the Savinja river on the map of Ljubno (numbered (1) in Fig. 1), and the Sava river on the map of Krško (numbered (5) in Fig. 1). Due to the fact that the satellite images were not acquired on the same day as the floods, they did not succeed completely in revealing the situation (with $32 \%$ coverage of the most affected river sections).

There are just $9 \mathrm{~km}$ of overlapping between the areas covered by the volunteered images and the satellite maps at a scale of 1:40000. The overlapping with detailed satellite maps on the scale of $1: 15000$ is even smaller, i.e., just $2.7 \mathrm{~km}$. Therefore, when summing the successful coverage of both methods together, $30 \%$ of the most affected river sections were mapped successfully.

\section{Discussion}

As this study has shown, the volunteered images can be gathered using two strategies. The first is with volunteered contributions and collaboration resulting from web page and Facebook announcements and social networking. The second is with a manual web search for useful, voluntarily presented images and then finding and asking the author if he/she is willing to cooperate as a contributor for the described purpose. The second strategy is much more time consuming, but gives the most acceptable and ready-to-use images for flood mapping with this research method. It resulted in the employment of a smaller number of images from a smaller number of contributors and the mapping of a broader area.

The first web search was performed within two weeks of the floods. Five months after the floods the web search was repeated to assess the total area of flooding. In the second search more structured web pages with image collections were also found. These image collections contained some potentially useful images for flood mapping in areas that were not covered by the first gathering of images. Therefore, for the future gathering of volunteered images for flood-mapping purposes it would be useful to repeat a web-search strategy, even a few months after the flooding. This might result in a greater share of useful images and a greater coverage of the flooded areas. Together with the images, very useful texts of local news were also found, which enabled a general localization of the extent of the flood. Such texts are a very useful part of the volunteered geographic information, which should be collected in future investigations.

As already mentioned by Scassa (2013), great care has to be taken to verify the authorship of the volunteered images and the resulting privacy issues. Additional guidelines need to be written for this purpose. The first rule, which must be obeyed, is that one always has to verify with the contributor of the image whether he or she is the author. In the case of this research, one third of the volunteer contributors sent us images from someone else. In any circumstances, the author of the image should be aware of the dissemination and usage of his/her work. Therefore, the author's approval is a must.

When finding useful images on the web, one also has to obtain the author's permission for free and open usage for the agreed task.

Even if the collaborating author provides an image and confirms that he/she is the real author, the user should always take care that no person or his/her recognizable belongings are on that image when the image is intended for publication. Even though this might be legally acceptable, it is not ethical from the point of view of privacy. Therefore, as already mentioned by Scassa (2013), any close-ups of courtyards and individuals or groups of people should be excluded. Such images can be used solely as internal information or as documentation.

In accordance with the above, the least problematic images are those showing broader areas (e.g., the panorama of a valley) or those taken from an elevated area or from the air (Fig. 2).

It is also important that the results of volunteered geographical information gathering are open to the general public and that the contributors are informed about the publication of results. This gives the contributors confirmation that their generous action was used for something worthwhile, and that it was beneficial for society. Prompt information might also help to motivate them to collaborate in similar future actions.

After having established fair personal contacts with the contributors, new opportunities could open up. The contributors could also be asked to photograph the consequences of the floods after the water has receded completely. With such a strategy, the volunteered geographical information can also be used to conduct multi-temporal studies of natural-disaster development.

Even though volunteered geographic information is free of charge, it needs extensive organizational efforts to acquire useful images for extensive flood mapping. If one relies only on volunteered images, some flooded areas can be missed completely. Therefore, to get a complete picture of the behavior of a natural disaster, other photogrammetrical or remotesensing sources should also be included in the study.

The derived flood maps can help us to improve the public's awareness and could be used to amend the spatial plans with actual flood events, etc. 


\section{Conclusions}

The floods of 5 and 6 November 2012 affected almost half of Slovenia. On 6 November 2012, an attempt to gather volunteered geographic information was begun. The images and video were gathered using two strategies: (1) volunteered contributions to public calls and (2) a web search of potentially useful images, with their authors being contacted. Volunteered images from 15 contributors enabled the flood mapping of $12 \%$ of the most affected river sections and data coverage of 1195.3 ha of flooded areas.

The results of the flood coverage using volunteered images were compared to the available GIO EMS mapping products, i.e., satellite maps. When judging the success of satellite flood mapping it was concluded that $18 \%$ of the most affected river sections were successfully mapped. This is due to the fact that the satellite images were acquired one to four days after the floods. The satellite images, however, covered $32 \%$ of the most affected river sections. There was only $5 \mathrm{~km}$ of overlap between the successful satellite and volunteered flood mapping. From this research it can be concluded that the volunteered image gathering represents a comparable, or even more accurate, alternative to satellite imagery. The volunteered images have, compared to the satellite images, some additional advantages. They give more detailed and more real-time results, as they represent the floods at the moment of the highest water. On the other hand, the results from the volunteered images do not give results as quickly as the automatic classification of water bodies from satellite images. Therefore, the future development of volunteered geographic information usage should strive for more automation in post-processing.

The final success of volunteered geographical image gathering depends mainly on the opportunity to gather the necessary images for flood-mapping purposes. Triggering an early social-networking action for collaborative image gathering plays a crucial role in obtaining coverage of areas that is as complete as possible.

Acknowledgements. This work was financially supported by Slovenian Research Agency project Z2-4182 (B). We are grateful to the Surveying and Mapping Authority of the Republic of Slovenia for the DTM and orthophoto images and to the Administration for Civil Protection and Disaster Management of the Ministry of Defence for the GIO EMS mapping products.

Edited by: P. Reichenbach

Reviewed by: T. Sprague and one anonymous referee

\section{References}

ARSO: Hidrološko poročilo o poplavah $\mathrm{v}$ dneh med 4. in 6 . novembrom 2012 (Hydrological report on the floods between 4 and 6 November 2012 - in Slovenian), available at: http: //www.arso.gov.si/vode/poro\%c4\%8dila\%20in\%20publikacije/ Poplave\%205.\%20-\%206.\%20november\%202012.pdf （last access: 25 March 2013) Environmental Agency of the Republic of Slovenia, Ljubljana, 15 pp., 2012.

COSMO-SkyMed: available at: http://www.cosmo-skymed.it/en/ index.htm (last access: 27 March 2013), 2013.

Dnevnik: available at: http://www.dnevnik.si/kronika/ koroska-pod-vodo-na-obmocju-crne-plazovi-in-hudourniki (last access: 10 March 2013), 2012.

Dravograd Municipality: available at: http://www.dravograd.si/ novice-in-obvestila/poplave-2012 (last access: 10 March 2013), 2012.

EMS - mapping portal: GMES emergency management service, available at: http://portal.ems-gmes.eu/frontend/ gio-ems-mapping.html (last access: 25 March 2013), 2013.

GIS: Poplave 2012 (Floods 2012 - in Slovene), available at: http://www.gis.si/sl/poplave-2012/\#rezultati, http://www.facebook.com/media/set/?set=a.397567120318940. 94236.170838432991811 (last access: 25 March 2013), Geodetic institute of Slovenia, Ljubljana, 2012.

Goodchild, M.: Citizens as sensors: the world of volunteered geography, GeoJurnal, 69, 211-221, 2007.

Karjalainen, M., Hyyppä, J., and Kuittinen, R.: Determination of exterior orientation using linear features from vector maps, Photogramm. Rec., 21, 329-341, 2006.

Lane, S. N., James, T. D., Pritchard, H., and Saunders, M.: Photogrammetric and laser altimetric reconstruction of water levels for extreme flood event analysis, Photogramm. Rec., 18, 293307, 2003.

McDougall, K.: An assessment of the contribution of the volunteered geographic information during recent natural disasters, Global Geospatial Conferenc 2012, 14-17 May, Quebec, Canada, 2012.

McDougall, K. and Temple-Watts, P.: The use of LIDAR and volunteered geographic information to map flood extents and inundation, ISPRS Annals of the Photogrammetry, Remote Sensing and Spatial Information Sciences, I-4, XXII ISPRS Congress 25 August-1 September, Melburne, Australia, 251-256, 2012.

Poser, K. and Dransch, D.: Volunteered geographic information for disaster management with application to rapid flood damage estimation, Geomatica, 64, 1, 89-98, 2010.

Rönnholm, P., Hyyppä, H., Pöntinen, P., Haggrén, H., and Hyyppä, J.: a method for interactive orientation of digital images using backprojection of 3-D data, The Photogrammetric Journal of Finland, 18, 16-31, 2003.

Rusjan, S., Kobold, M., and Mikoš, M.: Characteristics of the extreme rainfall event and consequent flash floods in W Slovenia in September 2007, Nat. Hazards Earth Syst. Sci., 9, 947-956, doi:10.5194/nhess-9-947-2009, 2009.

Scassa, T.: Legal issues with volunteered geographic information, Can. Geogr., 57, 1-10, 2013.

SMA RS: Digitalni model višin $5 \mathrm{~m} \times 5 \mathrm{~m}$ (DMV 5) (Digital terrain model $5 \mathrm{~m} \times 5 \mathrm{~m}$ (DTM 5) - in Slovene), available at: http://www.e-prostor.gov.si/zbirke_prostorskih_podatkov/ topografski_in_kartografski_podatki/digitalni_model_visin/ 
digitalni_model_visin_5_x_5_m_dmv_5/(last access: 25 March 2013), Survaying and Mapping Authority of Republic of Slovenia, 2013.

Schnebele, E. and Cervone, G.: Improving remote sensing flood assessment using volunteered geographical data, Nat. Hazards Earth Syst. Sci., 13, 669-677, doi:10.5194/nhess-13-669-2013, 2013.

Schumann, G. J.-P., Neal, J. C., Mason, D. C., and Bates, P. D.: The accuracy of sequential aerial photography and SAR data for observing flood dynamics, a case study of the UK summer 2007 floods, Remote Sens. Environ., 115, 2536-2546, 2011.
TerraSAR-X: available at: http://www.astrium-geo.com/en/ 228-terrasar- $\mathrm{X}$-technical-documents (last access: 25 March 2013), 2013.

Triglav-Čekada, M., Radovan, D., Gabrovec, M., and Kosmatin Fras, M.: Acquisition of the 3-D boundary of the Triglav glacier from archived non-metric panoramic images, Photogramm. Rec., 26, 111-129, 2011.

Velenje: available at: http://velenje.com/poplave2012/ (last access: 10 May 2013), 2012. 